\title{
A Review of Pharmacovigilance
}

\author{
JE Campbell ${ }^{1}$, M Gossell-Williams ${ }^{1}$, MG Lee ${ }^{2}$
}

\begin{abstract}
Pharmacovigilance supports safe and appropriate use of drugs. Spontaneous reporting of adverse drug reactions (ADRs) is an essential component of pharmacovigilance. However, there is significant underreporting of ADRs. Adverse drug reactions have become a major problem in developing countries. Knowledge of pharmacovigilance could form the basis for interventions aimed at improving reporting rates and decreasing ADRs.
\end{abstract}

Keywords: Adverse reaction, drug, pharmacovigilance, reporting

\section{Una Revisión de la Farmacovigilancia}

\author{
JE Campbell1 ${ }^{1}$, M Gossell-Williams ${ }^{1}$, MG Lee ${ }^{2}$
}

\section{RESUMEN}

La farmacovigilancia sustenta el uso seguro y apropiado de los medicamentos. La notificación espontánea de las reacciones adversas medicamentosas (RAM) es un componente esencial de la farmacovigilancia. Sin embargo, las notificaciones de RAM se quedan significativamente por debajo de las necesidades. Las reacciones adversas se han convertido en un problema grave en los países en vías de desarrollo. El conocimiento de la farmacovigilancia podría constituir la base de intervenciones dirigidas a mejorar las tasas de notificación y disminuir las RAMs.

Palabras claves: Reacción adversa, medicamento, farmacovigilancia, notificación

West Indian Med J 2014; 63 (7): 771

\section{INTRODUCTION}

Drugs have changed the way in which diseases are treated. Despite all the advantages of pharmacotherapy, adverse reactions are a recognized hazard of drug therapy. Adverse drug reactions (ADRs) are a common, frequently preventable cause of illness, disability and death. An ADR may be defined as "an appreciably harmful or unpleasant reaction, resulting from an intervention related to the use of a medi-

From: ${ }^{1}$ Department of Basic Medical Sciences and ${ }^{2}$ Department of Medicine, Faculty of Medical Sciences, The University of the West Indies, Kingston 7, Jamaica.

Correspondence: Dr JE Campbell, Pharmacology Section, Department of Basic Medical Sciences, Faculty of Medical Sciences, The University of the West Indies, Kingston 7, Jamaica. E-mail: jacqueline.campbel102@ uwimona.edu.jm

*The information in this review article was extracted from a thesis by the first author entitled "Assessment of the Knowledge and Attitude of Pharmacovigilance and Promoting the Importance of Adverse Drug Reaction Reporting among Physicians, Pharmacists and Dentists in Jamaica" which was in part fulfilment of a PhD in Pharmacology at the Department of Basic Medical Sciences, Faculty of Medical Sciences, The University of the West Indies, Mona, Jamaica. cinal product, which predicts hazard from future administration and warrants prevention or specific treatment, or alteration of the dosage regimen, or withdrawal of the product" (1).

Pharmacovigilance has been described as "the science and activities relating to the detection, assessment, understanding and prevention of the adverse effects of drugs or any other possible drug-related problems. It is a fundamental component of effective drug regulation systems, public health programmes and clinical practice" (2). Pharmacovigilance supports safe and appropriate use of drugs by a) promoting the detection of previously unknown ADRs and interactions and increases in frequency of known ADRs, b) identifying risk factors for the development of ADRs and c) estimating quantitative aspects of benefit/risk analysis and disseminating information to improve drug prescribing and regulation (3).

One of the first pieces of evidence of the establishment of a system to monitor drug safety was the committee set up by the Lancet to report on mortalities resulting from anaesthesia in Britain and its colonies. The formation of the committee was in reaction to the 1848 death of a 15 -year old 
girl who had undergone chloroform anaesthesia for the removal of an ingrown toenail $(4,5)$. In 1950, reports of cases of aplastic anaemia associated with the use of chloramphenicol were recorded in the United States of America [USA] (6). As a result, the Council on Drugs of the American Medical Association set up a Blood Dyscrasia Registry (7) and, by 1961, the Food and Drug Administration (FDA) began the systematic collection of reports of all types of ADRs, chiefly through the Hospital Reporting Program. However, it was a letter from Dr WG McBride which was published in the Lancet suggesting a connection between congenital malformations in newborn infants and the drug thalidomide that provided one of the most significant catalysts for drug safety monitoring. Thalidomide was first synthesized in 1954, introduced to the public in 1956 and was widely prescribed as a harmless treatment for morning sickness and nausea. By November 25, 1961, thalidomide was withdrawn from the market by its manufacturer. It has been estimated that between 6000 and 12000 children had been born with serious congenital malformations as a result of maternal use of thalidomide (8). By 1968, ten countries (Australia, Canada, Czechoslovakia, Germany, The Netherlands, Ireland, New Zealand, Sweden, United Kingdom, and USA), with national drug monitoring centres, collaborated and joined the World Health Organization (WHO) Pilot Research Project for International Drug Monitoring (5). In 1972, a report was published that formed the basis of the current international system of national centres collaborating in the WHO programme $(5,9,10)$.

The establishment of a pharmacovigilance system is essential to support public health policy. The study of Olsson et al (11), in which data regarding pharmacovigilance activities were collected from 55 low- and middle-income countries, revealed that information gathered through these activities was used in variable ways by the countries to assist regulatory functions, advise consumer groups and develop essential medicine lists and drug therapy guidelines.

\section{MORBIDITY AND MORTALITY OF ADRs}

Adverse drug reactions are ranked as one of the top 10 causes of morbidity and mortality in the developed world $(12,13)$. Adverse drug reactions are documented in the USA to claim 100000 to 218000 lives annually and are the third leading cause of death after heart disease and cancer (14-16). However, the burden of the problem may actually be underestimated, as in many instances, ADRs are not suspected, thereby leading to under-reporting $(17,18)$. Adverse drug reactions represent a vast economic burden in terms of healthcare costs, contribute to a significant percentage of hospital admissions and are regarded as a major public health problem (19-22). In the USA, the costs resulting from drugrelated problems in the ambulatory care setting was estimated to exceed US\$177 billion annually (15). These estimates are significant when compared with the healthrelated cost in the USA of other major diseases such as diabetes ( $\$ 174$ billion in 2007), obesity ( $\$ 147$ billon in 2009) and cardiovascular diseases [\$503 billion in 2010] (23-25).

Prior to approval, most drugs will only have been tested for short-term safety and efficacy on a limited number of carefully selected individuals (26). In some cases, as few as 500 subjects and seldom more than 5000 will have received the drug prior to its release (27). In order to identify an ADR that occurs in 1 in 10000 patients, at least 30000 patients need to be treated with the drug (2). Consequently, the limited numbers of persons involved in pre-marketing clinical trials do not facilitate good estimation of the ADR profile of a drug. Additionally, the controlled environment of pre-marketing clinical trials bears very little resemblance of how the drug is used in larger populations. It is after release, when the drug is used in more patients having a variety of concurrent diseases and who may be taking other drugs, that limitations to its use become evident. These limitations result from a paucity of long-term safety data, under-representation of certain populations in clinical trials and inadequate information regarding off-label use (28). Furthermore, the regular use of surrogate endpoints can give misleading information about the effects of drugs in comparison to usage in actual patients $(29,30)$. It is also during the post-approval phase that previously unidentified ADRs, many manifesting years after the release of a drug, may occur (31). This can be illustrated by the following example. Rhabdomyolysis is a serious but uncommon adverse effect of 3-hydroxy-3-methylglutaryl coenzyme A reductase inhibitors (statins). However, there have been reports of rhabdomyolysis occurring as a result of the interaction between azithromycin and various statins (32).

Post-approval monitoring facilitates observation of the drug profile for longer durations and for unapproved indications, effects of co-morbidities, co-administrations and the likely possibility of non-compliance with drug administration instructions.

Signal detection is one of the primary goals of pharmacovigilance $(33,34)$. A signal is defined by the WHO as reported information on a possible causal relationship between an adverse event and drug, the relationship being unknown or incompletely documented previously. Usually more than one report is required to generate a signal, depending on the seriousness of the event and the quality of the information $(35,36)$. When detected, signals should be followed up with detailed investigations including pharmacoepidemiological studies (33) and appropriate regulatory action (37).

\section{METHODS OF QUANTIFYING ADRs}

A number of methods have been used to quantify the frequency of ADRs. They include spontaneous ADR reporting, ecological studies and analyses of medical claims databases, prescription-event monitoring which collects all drug-related events that occur while patients are receiving selected monitored medications, and meta-analyses (38-41). No 
single method is capable of covering all the requirements for the efficient collection of ADR data and therefore a multiplicity of methods is needed (42).

Spontaneous reporting is the most common method used in pharmacovigilance and the best one to generate signals on new or rare ADRs (43). This reporting scheme has contributed significantly to successful post-marketing drug safety surveillance and can be regarded as the cornerstone of pharmacovigilance (44). There are numerous limitations of the scheme, including the poor quality of submitted reports, difficulty in calculating rates because of incomplete numerator (adverse events) data along with inaccurate denominators (number of prescriptions) and limited ability to determine causality $(13,45)$. However, the main limitation is under-reporting $(26,43,45-48)$.

In a review of 37 studies from 12 countries, undertaken to estimate the extent of under-reporting of ADRs to spontaneous reporting systems, Hazell and Shakir (49) reported a median under-reporting rate of $94 \%$ across these studies. Perez-Garcia and Figueras (50), in a study of physicians and pharmacists in Venezuela, reported poor knowledge of the voluntary ADR reporting system in that country. They concluded that study of the actual knowledge of pharmacovigilance could form the basis for specifically designed interventions aimed at overcoming misconceptions and improving reporting rates.

In Jamaica, ADR reports are made to the regulatory authority, the Standards and Regulation Division, Ministry of Health. The standardized ADR reporting form is the "PharmWatch" form (51). A study of the knowledge and attitude of healthcare professionals toward pharmacovigilance and ADR reporting identified training as a significant factor in the improvement of the reporting of ADRs (52). Subsequently, a workshop that could i) facilitate training in the sensitization of healthcare professionals to the importance of pharmacovigilance and ii) effect an improvement in ADR reporting through understanding the importance of the "PharmWatch" pharmacovigilance programme was designed. The workshop attendees indicated that the workshops encouraged them to report ADRs. These findings provide evidence that the training of healthcare professionals can positively impact the rates of ADR under-reporting. Further education and training are urgently needed.

\section{REFERENCES}

1. Edwards IR, Aronson JK. Adverse drug reactions: definitions, diagnosis, and management. Lancet 2000; 356: 1255-59.

2. World Health Organization. Safety of medicines. A guide to detecting and reporting adverse drug reactions - why health professionals need to take action. Geneva: World Health Organization; 2002.

3. World Health Organization. Safety monitoring of medicinal products: guidelines for setting up and running a pharmacovigilance centre. Uppsala: Uppsala Monitoring Centre, World Health Organization; 2000

4. Routledge P. 150 years of pharmacovigilance. Lancet 1998; 351: 1200 1 .
5. van Grootheest K. The dawn of pharmacovigilance. Intern J Pharm Med 2003; 17: 195-200.

6. Rich ML. Fatal case of aplastic anaemia following chloramphenicol therapy. Ann Intern Med 1950; 33: 1459.

7. Wallerstein RO, Condit PK, Kasper CK, Brown JW, Morrison FR. Statewide study of chloramphenicol therapy and fatal aplastic anemia. JAMA 1969; 208: 2045-50.

8. Randall T. Thalidomide's back in the news, but in more favorable circumstances. JAMA 1990; 263: 1467-8.

9. Olsson S. The role of the WHO Programme on international drug monitoring in coordinating worldwide drug safety efforts. Drug Saf 1998; 19: $1-10$.

10. World Health Organization. International drug monitoring: the role of national centres. Geneva: World Health Organization; 1972.

11. Olsson S, Pal S, Stergachis A, Couper M. Pharmacovigilance activities in 55 low- and middle-income countries. Drug Saf 2010; 33: 689-703.

12. Lazarou J, Pomeranz BH, Corey P. Incidence of adverse drug reactions in hospitalized patients: a meta-analysis of prospective studies. JAMA 1998; 279: $1200-5$

13. Pillans PI. Clinical perspectives in drug safety and adverse drug reactions. Expert Rev Clin Pharmacol [serial on the Internet] 2008; 1: 695-705. doi: 10.1586/17512433.1.5.695. Available from: http://www. medscape.com/viewarticle/583670

14. Aspinall MB, Whittle J, Aspinall SL, Maher RL Jr, Good CB. Improving adverse-drug-reaction reporting in ambulatory care clinics at a Veterans Affairs hospital. Amer J Health Syst Pharm 2002; 59: 8415 .

15. Ernst FR, Grizzle AJ. Drug-related morbidity and mortality: updating the cost-of-illness model. J Am Pharm Assoc (Wash) 2001; 41: 192-9.

16. White TJ, Arakelian A, Rho JP. Counting the costs of drug-related adverse events. Pharmacoeconomics 1999; 15: 445-58.

17. Benkirane R, Pariente A, Achour S, Ouammi L, Azzouzi A, Soulaymani R. Prevalence and preventability of adverse drug events in a teaching hospital: a cross-sectional study. East Mediterr Health J 2009; 15: $1145-55$.

18. Jones J. Adverse drug reactions in the community health setting: approaches to recognizing, counselling, and reporting. Fam Community Health 1982; 5: 58-67.

19. Brvar M, Fokter N, Bunc M, Mozina M. The frequency of adverse drug reaction related admissions according to method of detection, admission urgency and medical department specialty. BMC Clin Pharmacol 2009; 9: 8. doi: 10.1186/1472-6904-9-8.

20. Carmago AL, Cardoso Ferreira MB, Heineck I. Adverse drug reactions: a cohort study in internal medicine units at a university hospital. Eur J Clin Pharmacol 2006; 62: 143-9.

21. Patel KJ, Kedia MS, Bajpai D, Mehta SS, Kshirsagar NA, Gogtay NJ. Evaluation of the prevalence and economic burden of adverse drug reactions presenting to the medical emergency department of a tertiary referral centre: a prospective study. BMC Clin Pharmacol 2007; 7: 8.

22. Zolezzi M, Parsotam N. Adverse drug reaction reporting in New Zealand: implications for pharmacists. Ther Clin Risk Manag 2005; 1: $181-8$.

23. Centers for Disease Control and Prevention. National diabetes fact sheet: national estimates and general information on diabetes and prediabetes in the United States. Atlanta, GA: US Department of Health and Human Services, Centers for Disease Control and Prevention. Available from: http://www.cdc.org

24. Finklestein EA, Trogdon JG, Cohen JW, Dietz W. Annual medical spending attributable to obesity: payer- and service-specific estimates. Health Aff (Millwood) 2009; 28: w822-31. doi: 10.1377/hlthaff. 28.5.w822. Epub 2009 Jul 27.

25. Lloyd-Jones D, Adams RJ, Brown TM, Carnethon M, Dai S, De Simone $\mathrm{G}$ et al. Executive summary: heart disease and stroke statistics-2010 update. Circulation 2010; 121: 948-54

26. Wysowski DK, Swartz L. Adverse drug event surveillance and drug withdrawals in the United States, 1969-2002: the importance of reporting suspected reactions. Arch Intern Med 2005; 165: 1363-9. 
27. World Health Organization. Pharmacovigilance: ensuring the safe use of medicines. In: WHO Policy Perspectives on Medicines. Geneva: World Health Organization; 2004.

28. Stafford RS. Regulating off-label drug use: rethinking the role of the FDA. N Engl J Med 2008; 358: 1427-9.

29. Fleming TR, DeMets DL. Surrogate end points in clinical trials: are we being misled? Ann Inter Med 1996; 125: 605-13.

30. Ray WA, Stein CM. Reform of drug regulation - beyond an independent drug-safety board. N Engl J Med 2006; 354: 194-201.

31. Pirmohamed M, Breckenridge A, Kitteringham NR, Park B. Adverse drug reactions. Br Med J 1998; 316: 1295-8.

32. Strandell J, Bate A, Hägg S, Edwards IR. Rhabdomyolysis a result of azithromycin and statins: an unrecognized interaction. $\mathrm{Br} \mathrm{J}$ Clin Pharmacol 2009; 68: 427-34.

33. Egberts TCG. Signal detection: historical background. Drug Saf 2007; 30: 607-9.

34. Hauben M, Reich L. Communication of findings in pharmacovigilance: use of the term "signal" and the need for precision in its use. Eur J Clin Pharmacol 2005; 61: 479-80.

35. Edwards IR, Biriell C. Harmonisation of pharmacovigilance. Drug Saf 1994; 10: 93-102.

36. Stahl M, Edwards IR, Bowring G, Kiuru A, Lindquist M. Assessing the impact of drug safety signals from the WHO database presented in 'SIGNAL': results from a questionnaire of national pharmacovigilance centers. Drug Saf 2003; 26: 721-7.

37. Hochberg AM, Reisinger SJ, Perason RK, O'Hara DJ, Hall K. Using data mining to predict safety actions from FDA adverse event reporting system data. Drug Inf J 2007; 41: 633-43.

38. Gibbons RD, Amatya AK, Brown CH, Hur K, Marcus SM, Bhaumik DK et al. Post-approval drug safety surveillance. Annu Rev Public Health 2010; 31: 419-37. doi: 10.1146/annurev.publhealth. 012809.103649

39. Blenkinsopp A, Wilkie P, Wang M, Routledge PA. Patient reporting of suspected adverse drug reactions: a review of published literature and international experience. Br J Clin Pharmacol 2007; 63: 148-56.
40. Lazarou J, Pomeranz BH, Corey P. Incidence of adverse drug reactions in hospitalized patients: a meta-analysis of prospective studies. JAMA 1998; 279: 1200-5.

41. Pirmohamed M, James S, Meakin S, Green C, Scott A, Walley T et al. Adverse drug reactions as cause of admission to hospital: prospective analysis of 18820 patients. Br Med J 2004; 329: 15-9.

42. Fletcher AP. Spontaneous adverse drug reaction reporting vs. event monitoring: a comparison. J Royal Soc Med 1991; 84: 341-4.

43. Alvarez-Requejo A, Carvajal A, Begaud B, Moride Y, Vega T, Martin Arias LH. Under-reporting of adverse drug reactions: estimate based on a spontaneous reporting scheme and a sentinel system. Eur J Clin Pharmacol 1998; 54: 483-8.

44. Pirmohamed M, Breckenridge A, Kitteringham NR, Park B. Adverse drug reactions. Br Med J 1998; 316: 1295-8.

45. Lexchin J. Is there still a role for spontaneous reporting of adverse drug reactions? CMAJ 2006; 174: 191-2.

46. Lexchin J. Drug withdrawals from the Canadian market for safety reasons, 1963-2004. CMAJ 2005; 172: 765-7.

47. Lopez-Gonzalez E, Herdeiro MT, Figueiras A. Determinants of underreporting of adverse drug reactions: a systematic review. Drug Saf 2009; 2: 19-31.

48. Martin RM, Kapoor KV, Wilton LV, Mann RD. Underreporting of suspected adverse drug reactions to newly marketed ("black triangle") drugs in general practice: observational study. Br Med J 1998; 317: 119-20.

49. Hazell L, Shakir SA. Under-reporting of adverse drug reactions: a systematic review. Drug Saf 2006; 29: 385-96.

50. Pérez García M, Figueras A. The lack of knowledge about the voluntary reporting system of adverse drug reactions as a major cause of underreporting: direct survey among health professionals. Pharmacoepidemiol Drug Saf 2011; 20: 1295-302.

51. Gossell-Williams M, Adebayo S. The PharmWatch programme: challenges to engaging the community pharmacists in Jamaica. Pharm Pract (Granada) 2008; 6: 187-90.

52. Campbell JE. Assessment of the knowledge and attitude of pharmacovigilance and promoting the importance of adverse drug reaction reporting among physicians, pharmacists and dentists in Jamaica $[\mathrm{PhD}$ thesis]. Kingston: University of the West Indies; 2013. 